\title{
Improving Internal Communication Management in SMEs: Two Case Studies in Service Design
}

\section{Tuomo Eskelinen, Mervi Rajahonka, Kaija Villman, and Ulla Santti}

\author{
"In most people's vocabularies, design means") \\ veneer. It's interior decorating. It's the fabric of \\ the curtains and the sofa. But to me, nothing \\ could be further from the meaning of design.
}

Steve Jobs (1955-2011)

Co-founder of Apple and Pixar

\begin{abstract}
Effective information management is a success factor for business growth, but small and medium-sized enterprises (SMEs) face challenges in transferring knowledge and information from one organizational unit to another. In this study of two case companies, participative business model development processes were designed to identify challenges and solutions in internal communication management. A service design approach based on CIMO logic (context, intervention, mechanism, and output) showed that the participative business model technique and process can identify problems and challenges in internal communication management, as well as in the prioritization of actions. The process is a creative service design process including both divergent and convergent phases. The process increased motivation among personnel to find solutions, encouraged communication, and created joint understanding on how to solve problems. The technique helped to bring tacit information into use.
\end{abstract}

\section{Introduction}

Service and product innovation is a knowledge-intensive process (e.g., Balasubramanian \& Tiwana, 1999). It can be described as an information-transformation process where information is gathered, processed, and transferred in a creative way. Obviously, communication is a vital and basic need, but it is also an opportunity for service and product innovation. This latter aspect is particularly important when team members are separated by geographical distances or when they work in shifts. External communication is also important for successful product innovation (e.g., Mendelson \& Pillai, 1999). Communication and collaboration are therefore identified as critical factors for successful product and service innovation management.

A crucial innovation management problem in a small and medium-sized enterprise (SME) is communication inside the company, between its departments (Katcher, 2017; Zeithaml, 1988). For example, poor communication management between sales or marketing and pro- duction departments causes delays in the delivery of products or services, or quality problems connected to the production process or the product or service itself. Likewise, process communication is important, whether it is external (e.g., communicating with a client) or internal (e.g., communicating within a service-providing organization) (Moritz, 2005).

Many technological solutions have been developed for improving communication management, including collaborative platforms and social media applications. Also, employees use instant messaging as an additional means reaching others in real time, although it has an interruptive nature so management should pay attention to the quality and content of employees instant messaging (Cameron \& Webster, 2005). However, there are still very few practical examples of how these technologies have been successfully implemented in SMEs, and many employees recognize that they should be getting more value from these tools. The main purpose of information management technologies should be to help workers do their work. They should also support 


\title{
Improving Internal Communication Management in SMEs
}

\author{
Tuomo Eskelinen, Mervi Rajahonka, Kaija Villman, and Ulla Santti
}

teamwork and increase innovation and productivity. In addition, management needs information to support their staff, to increase effectiveness, and perform their own job better (Hamilton et al., 2016; Heckscher \& Adler, 2007). Effective internal communication is crucial for successful organizations because it helps strategic managers to engage employees and achieve objectives (Welch \& Jackson, 2007).

Pervaiz (1998) stated that the most innovative companies are those that manage to create appropriate cultures and climate that nurture innovation and creativity. Moreover, innovativeness with open organizational culture and market orientation has positive effects on organizational performance (Deshpandé \& Farley, 2004; Deshpandé et al., 2000). Effective internal communication may increase the synergy effect with employees as ambassadors and improve company's marketing and public relations functions (Nielsen \& Thomsen, 2009). Varey (1995) noticed that internal marketing may considerably increase competitive effectiveness by continuous improvement and culture change processes and also wondered what tactics and mechanisms may be used to translate information.

In this article, we describe our study of the challenges and solutions in internal communication management in two case companies. After developing the companies' communication processes, we inspected the effects on the company's organizational culture caused by the issued changes. We used service design and business model development approaches, and we tested how these approaches can be used in the context of internal communication challenges. We claim that business model tools can be used in a service design process. There are certain advantages in using service design and business model approaches instead of, for example, the business process management approach, which emphasizes improving performance by optimizing a company's business processes. Both service design and business model approaches are more multidimensional: they include customer and user perspectives in addition to the company's views. Furthermore, they include elements of conceptualization/social construction (through idea generation and selection), development or design (including design of better internal processes), and implementation of changes (Morelli, 2002; Nisula, 2012; Osterwalder \& Pigneur, 2010). In other words, they both contain divergent and convergent phases, as typical in service design (e.g., Moritz, 2005).
Business model tools may help industrial companies to better utilize the insights of their own business processes and internal communication - and those of their business customers - and to design integrated solutions that correspond with their customers' needs (Ojasalo, 2017). The business model canvas by Osterwalder and Pigneur (2010) can be applied to cover both the industrial company's viewpoint (value capture) and its customers' viewpoint (value creation) (Ojasalo \& Ojasalo, 2015). Interaction and co-production are essential elements of the service logic business model canvas, introduced by Ojasalo and Ojasalo (2015). According to Ojasalo (2017), the key questions relate to how to facilitate the interaction between the company and its customers, what the customer's mental models of interacting with the company are, and how the company can support the customer co-production and the interaction between the company and the customer. The service logic business model canvas includes a specific block on interaction and co-production, which is connected to internal communication. However, internal communication in this context has not been the focus of other studies, which appears to present an obvious gap of knowledge.

Design thinking in our study means that problems and opportunities are framed from a human-centred perspective, trying to engage potential users and stakeholders, and we use visual methods to explore and generate ideas (e.g., Brown, 2008, as cited by Kimbell, 2011). Our research questions are:

1. How can SMEs overcome the challenges of internal information management by involving all the stakeholders necessary for a successful service design process?

2. How can service design tools and processes, such as participative business model techniques, be used in the identification of communication management problems and solutions inside SMEs?

Our approach to answering these questions and the resulting findings are described below. First, we introduce the project from which the two cases were drawn and the service design tools and methods that were applied to each case company. We also describe our analytical approach, which used CIMO logic (context, intervention, mechanism, and output). Next, we present and discuss our findings. Finally, we offer conclusions, with a particular emphasis on their implications for SMEs. 


\title{
Improving Internal Communication Management in SMEs
}

\author{
Tuomo Eskelinen, Mervi Rajahonka, Kaija Villman, and Ulla Santti
}

\section{Methods}

This research is based on two case studies where participative business model techniques were used as part of an innovation process to identify internal communication challenges and solutions. The participative process and tools used include interviews, discussions, and brainstorming. We believe that these methods can be used to uncover explicit user information and reveal tacit knowledge from the employees (Sanders \& Dandavate, 1999).

The case companies in this research were participants in the Pake Savo project (Eskelinen et al., 2017), which is a joint project of Finnish universities: the South-Eastern Finland University of Applied Sciences XAMK and the Savonia University of Applied Sciences. The case companies were selected from about 20 SMEs who participated in the Pake Savo project. The selection criteria were a need to develop internal communication and willingness to design a participative development process. The two-year project began in 2015 and was financed by the European Social Fund. The purpose of the project was to help SMEs located in the Northern Savo (Eastern Finland) to start or develop their service business. In today's rapidly changing business environment, SMEs need to develop new innovative service concepts. Therefore, Pake Savo project aimed to advance new business creation and productivity in the participating SMEs, which were from the service and manufacturing industries. The Pake Savo project arranged two training packages on service design for the SMEs. The training was developed and delivered by the two participating universities of applied sciences. Selected external experts also delivered training modules. Related to the training sessions, each company carried out a development project associated with each company's service business. In these development projects, the participants learned, for example, how to apply the training on service design methods and the business model approach to their companies.

Several of the companies used the InTo business model analysis tool (into.savonia.fi), which was developed in Savonia (see Kajanus et al. 2014), to select the development project or to prioritize key development targets. The Into analysis enables personnel to be involved in and committed to the process from the beginning. The selected themes of the development tasks included the development of new service concepts or service products, better customer service or internal processes, and more fluent information flows. The development projects showed that, in a customer-oriented company, effective internal communication is essential. In other words, only if internal communication processes work well, can a truly customer-oriented service approach become a reality. The shift from a product-oriented company to a customer-oriented company cannot succeed without a major change in the organization's culture. As a part of the training (i.e., the Training Programme on Service Design, Pake Savo, 2015-2017), the SMEs applied a service design approach in their company to develop their businesses, especially to develop new innovative products and services. Typical development topics for service design are process development and development of offerings, and development of marketing, sales, organization, or business strategy (Koivisto, 2014; Miettinen \& Koivisto, 2009). Development of new offerings means that they differ from the previous ones, for example, from the point of view of the operating model, customer value, revenue logic, target group, or user experience.

In the two case SMEs, internal communication management was identified as a key problem. Participative business model techniques were used in the identification of communication management problems. Business model techniques can be used in a business design process of an SME aiming to create strategies, reasoning, insights, and improvements in communication. Kajanus and colleagues (2014) have presented a process for business model creation by using multiple-criteria decision support techniques and portfolio analysis. These techniques were now applied to facilitate the communication development process. The researchers designed and realized separate innovation processes in the two case companies together with the management teams and a development group consisting of employees.

Company A produces high-quality furniture and components for different purposes, such as ergonomic furniture constructed hygienic Corian material. Before the training started, the researchers asked the company to fill in a questionnaire, which contained questions on development needs. Development needs and challenges were also identified and discussed during a site visit. Based on the results, internal communication between production, marketing, and delivery of products was identified as a key challenge. A business model development process was designed and performed during 2015. The process contained five steps: i) context design, ii) idea generation, based on interviews of the CEO and application of the web-based Savonia InTo innovation tool (into.savonia.fi), iii) evaluation of ideas against two criteria: improvement of internal communication and management of customer relationships, iv) core index 


\section{Improving Internal Communication Management in SMEs}

\section{Tuomo Eskelinen, Mervi Rajahonka, Kaija Villman, and Ulla Santti}

analysis, according to Kajanus and colleagues (2014), and v) discussions with personnel on the results and actions (Figure 1). The general theme was defined as developing internal communication and customer relationships management as part of the company's business model. The ideas could be connected to customer needs, to the value produced for the customer, sales channels, development and maintenance of customer relationships, key resources, key activities, or key partners. Company A's goal is to find the ideas and actions that will enable them to deliver products to the customer in an efficient and timely manner. The process produced 28 ideas and 23 comments on those ideas. All company personnel participated in the generation of the ideas and the evaluation and discussion of the best ideas. The best ideas were selected with the help of the core index method and discussions. The goal was to bring the best ideas into practice.

Company B also participated in the Training Programme on Service Design (Pake Savo 2015-2017), filled in the questionnaire on development challenges and needs, and hosted a visit by researchers. Visits were undertaken by service design and business development researchers from the participating universities.
The company is highly innovative, as indicated by its 100 patents. It designs, manufactures, and markets repair equipment and measuring systems for collisiondamaged vehicles. Based on the results of the analysis, internal communication between production, marketing, and sales departments was identified as a major challenge in developing the company's business model. Communication errors have led to many problems, such as delays in the information chain from client to production. When clients need architectural or other changes, for example a change of equipment, information needs to reach all people in the production chain very quickly. The internal communication development process was designed and implemented in 2016. It contained context and participant definition, idea generation with six questions on internal communication challenges, idea evaluation against selected criteria, core index analysis of results according to Kajanus and colleagues (2014), and a workshop to discuss the results and decide actions. There were four evaluation criteria for ideas in the evaluation phase: i) improvement of internal communication, ii) feasibility, iii) increase in productivity and turnover, and iv) cost-benefit value. The process created 32 new ideas and four complete evaluations against the evaluation

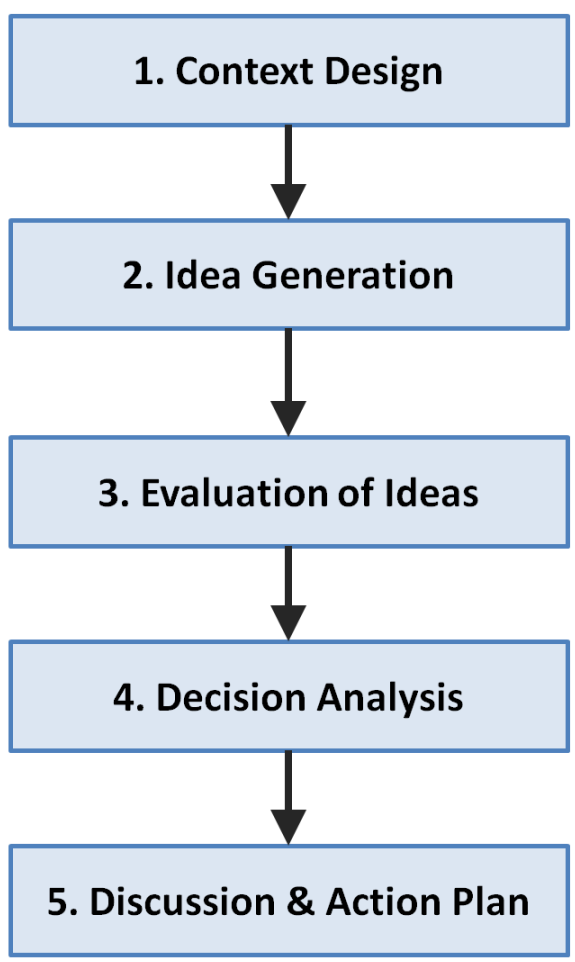

- Problem area pain chain

- Who, how, and when?

- Multicriteria setting

- Interviews: face to face, phone, small groups

- Brainstorming (different methods)

- Input by net link

- Multicriteria evaluation of idea with a web tool

- With core value and portfolio analysis

- Discussion of results

- Creation of action plan

Figure 1. Participative development process for business model techniques (adapted from Kajanus et al., 2014) 


\section{Improving Internal Communication Management in SMEs}

\section{Tuomo Eskelinen, Mervi Rajahonka, Kaija Villman, and Ulla Santti}

criteria, all of which were analyzed with core index analysis. The ideas were prioritized according to their core index.

Next, CIMO logic (context, intervention, mechanism, and output) was used to describe and analyze the two case studies (Denyer et al., 2008). The purpose of working with CIMO logic is to produce design propositions for enabling understanding and insights of the explored phenomena. A proposition with CIMO logic is formed as follows: for a problematic context, use some specific intervention that will invoke some generative mechanisms that in turn will deliver the desired outcome. The propositions thus not only inform what should be done in a specific situation in order to create a specific effect, but more importantly, they offer insight on why it happens (Denyer et al., 2008; Proper et al., 2010). CIMO logic has been used, for example, to analyze public health sector innovations (Batterham et al., 2014; Proper et al., 2010) and to establish a set of design principles to foster the development of teacher communities in secondary education (Brouer et al., 2012).

\section{Findings}

The main results of the study are novel methods and innovative tools to identify information management problems, and testing of these tools with solutions piloted in practice in SMEs. The solutions brought about improvements in information management in the case companies. In addition, changes and developments in the communication management and organizational culture are observed and discussed. The main results of the analysis based on CIMO logic (context, intervention, mechanism, and output) are presented in Table 1.

The results were obtained, in the case of Company A, one year after the development process had been finished, and, in case of Company B, only one month after. For this reason, the responses from Company $B$ are interpreted as "goals" in comparison to Company A, whose answers are interpreted as "actualized" items. Company A established a computer-based solution that aims to facilitate more effective communication between the departments, and the solution has been tested and piloted with some clients.

Table 1. Results of CIMO logic analysis (Denyer et al., 2008) of the participative business model techniques for development processes in Companies A and B

\begin{tabular}{lll}
\hline CIMO & Company A & Company B \\
\hline Context & $\begin{array}{l}\text { A Finnish company offering tailored wood and } \\
\text { composite based products, such as acoustical elements } \\
\text { for loudspeakers. }\end{array}$ & $\begin{array}{l}\text { A Finnish company that designs, manufactures, and } \\
\text { markets repair equipment and measuring systems for } \\
\text { repairing collision-damaged vehicles. }\end{array}$ \\
& $\begin{array}{l}\text { Challenges lie in developing internal communication } \\
\text { between production, marketing, and delivery of } \\
\text { products }\end{array}$ & $\begin{array}{l}\text { Challenges lie in internal communication between } \\
\text { production, marketing, and sales departments. }\end{array}$ \\
\hline Intervention & $\begin{array}{l}\text { Business model development process to find new ideas } \\
\text { and solutions. }\end{array}$ & $\begin{array}{l}\text { Development process to find ideas and solutions to } \\
\text { develop internal communication. }\end{array}$ \\
\hline Mechanism & $\begin{array}{l}\text { Abusiness model development process: context } \\
\text { definition, idea creation with interviews and web link, } \\
\text { multi-criteria idea evaluation with a web based tool, } \\
\text { portfolio analysis of results and workshop }\end{array}$ & $\begin{array}{l}\text { A development process with six questions on } \\
\text { challenges in internal communication, idea creation } \\
\text { in a workshop, external expert visit to accelerate } \\
\text { creation of new ideas, idea evaluation with a web } \\
\text { tool, multi-criteria evaluation of ideas, portfolio } \\
\text { analysis of results, and a workshop }\end{array}$ \\
& & $\begin{array}{l}\text { Prioritized list of actions. A decision was made to } \\
\text { improve, test, and pilot an internal communication } \\
\text { system. }\end{array}$ \\
\hline Output & $\begin{array}{l}\text { Two solutions were identified and put into practice. A } \\
\text { WhatsApp application was tested and found useful. }\end{array}$ & \\
\hline
\end{tabular}




\title{
Improving Internal Communication Management in SMEs
}

\author{
Tuomo Eskelinen, Mervi Rajahonka, Kaija Villman, and Ulla Santti
}

For example, if the marketing department discovers changes in the customer needs, they communicate directly with the production team, and the development and management departments. Or, if the production team discovers that they need more material, they communicate with the planning department. Company A reports that they have already achieved higher efficiency with one larger client. Previously, a project delivery with a client was delayed due to many changes in customer specifications. In this case, when the client needed different colours, and at the same time, the project developer could not keep the original schedule, dealing with these changes caused a cost of $€ 20,000$. Moreover, because of improvements in the internal communication process, clients receive their invoices more quickly and efficiently. Furthermore, the new communication system has proved to be efficient in several other situations. Previously, the information chain was not functioning well, but now, because of the new information system, the information reaches the right recipients in an intelligent way. For example, after the information comes from the client, it is delivered directly to the machining department unit where the changes to the product are done. Another example is when the marketing department recognizes a need to change or improve a product, they negotiate with the client and inform the production department. All information is delivered with a centralized system using email, WhatsApp (www.whatsapp.com), and an implementation system developed by the company. The process applies lean information management to eliminate wasting of time and to increase speed (George, 2002).

The management of Company A claims that the "most important ideas may rise from the most silent worker". The development process was useful because tacit information was made available and the silent workers' ideas were recognized and heard. The management group encourages new ideas to improve internal communication. On the other hand, there has been some resistance against changes. Moreover, not all workers have had the same communication tools, which have delayed the improvement process in internal communication. In the future, Company A will look for new training activities that target further time and production efficiency as well as improving efficiency in internal communication management.

In Company B, internal communication was chosen as the development topic because many challenges had been faced. Information did not reach the right people at the right time. As a very important development question, Company B's goal was that the managers and bosses should know at all times what is happening in the field and are aware of any reclamations. The company estimated that a substantial improvement was gained as a result of the development process. As another result, an internal communication system was identified as a solution and it now has been piloted with users. Since only a short time has passed after the development process was finished, not all the decisions to improve internal communication have been put into action. Company B's experience of the development process has been that it committed and inspired employees and made the problems clearer and more understandable to all. The next step would be putting the solutions into practice. Also, the personnel's motivation has increased, and it seems that all are doing their best to improve internal communication. There is more discussion and awareness of the challenges. Overall, the development process helped to gain a joint insight on what the problems, challenges, and solutions are in internal communication management. Moreover, it was important to find tacit ideas from the silent workers. As the next step, development needs were identified in order to design and put into practice a digital information management system. For this purpose, Company B and Company A also shared knowledge on solutions as part of the Training Programme. Company $\mathrm{B}$ also has decided to develop their meeting routines.

\section{Conclusion}

Service design was in the focus of the training programme in which both Companies A and B participated. As feedback, the companies stated that service design methods offer many new possibilities and the training programme increased their knowledge on service design methods as well as collaboration. Of particular importance was the identification of customer needs with service design tools and methods. In addition, tacit information from the employees was brought into practical ideas and solutions with the InTo tool based on a business model approach.

This research presents a systematic business model process, which is efficient in the identification of communication management problems and challenges. Second, it presents the application of the process into two practical cases that illustrate how improvements of internal communication management challenges can be realized in practice. This systematic process and the practical cases create effectiveness and enhance new innovations in the ways how internal communication is managed in SMEs. However, in particular, applying participative business model techniques in the context of 


\title{
Improving Internal Communication Management in SMEs
}

\author{
Tuomo Eskelinen, Mervi Rajahonka, Kaija Villman, and Ulla Santti
}

service design has proven to be a very successful approach. Consequently, the process becomes more multidimensional, customer-oriented, and includes both divergent and convergent phases, and creativity, as typical to service design (e.g., Moritz, 2005). For example, Company B's new product innovation has started from customer needs, namely the need garages have for a productive and fluent service chain when they offer services to their clients who bring cars to the garage for repairs. For garages, the need is to "get the job done easily". The customer feedback on the new product has been very good. Company B actively thinks about customer needs and even the "needs of the customers of their customer".

The service design training programme was linked to real business needs and resulted in measurable improvements in internal communication in the participating SMEs without forgetting the customer perspective. The process including participative business model techniques increases interaction inside the company; interaction is needed when creating more user-oriented services (Miettinen \& Koivisto, 2009). The process also increased motivation of the personnel to solve both internal problems and customers' problems.

All SMEs could potentially benefit from the findings of this research. Problems in internal communication management cause many difficulties, which even affect the final customer and end-user satisfaction. Practical case examples also demonstrate that cost-effective solutions are available to improve internal communication management. Better communication management helps workers and executives perform their work better and faster, solve problems more quickly, as well as deliver more value for their customers.

\section{Acknowledgments}

We wish to thank the case companies for their valuable cooperation and support to this study. The study was partly financed by the European Social Fund.

An earlier version of this article was presented at the ISPIM Innovation Forum in Toronto, Canada, March 19-22, 2017. ISPIM (ispim-innovation.com) - the International Society for Professional Innovation Management - is a network of researchers, industrialists, consultants, and public bodies who share an interest in innovation management.

\section{About the Authors}

Tuomo Eskelinen, PhD, works as an RDI Advisor at the Savonia University of Applied Sciences in Finland. His background is in Environmental Sciences, and his expertise and research interests include sustainable value networks, development of business partnerships, and sustainable business models. He organizes research, development, and innovation processes with enterprises and other organizations, with scientists, end users, and customers, from idea generation to business models development and commercialization. He has participated in more than $20 \mathrm{EU}$-funded projects in the fields of forestry, energy, food, water safety, and processing. He is experienced in performing and coordinating interdisciplinary, international, large-scale research projects, workshops and training.

Mervi Rajahonka, DSc (Econ), works as an RDI Advisor at the Small Business Center (SBC), currently a part of the South-Eastern Finland University of Applied Sciences XAMK, Finland. She has been working at the SBC for about 10 years, participating in numerous EU-funded projects. She earned her doctoral degree in Logistics from the Department of Information and Service Economy at Aalto University School of Business in Helsinki, Finland. She also holds a Master's degree in Technology from the Helsinki University of Technology and a Master's degree in Law from the University of Helsinki. Her research interests include sustainable logistics and supply chain management, business models, service modularity, and service innovations. Her research has been published in a number of journals in the areas of logistics, services, and operations management.

Kaija Villman, MMus in Arts management, works as a Project Manager at the South-Eastern Finland University of Applied Sciences XAMK, Small Business Center, Finland. She has been working at the SBC for about 7 years, participating in numerous EU-funded projects in the fields of creative industries, service development, and digitalization. She is experienced in coordinating interdisciplinary projects, workshops, and training and she acted as the Project Manager for the PaKe Savo Project.

\section{Continued on next page...}




\section{Improving Internal Communication Management in SMEs}

\section{Tuomo Eskelinen, Mervi Rajahonka, Kaija Villman, and Ulla Santti}

\section{Continued...}

Ulla Santti, MSc (Econ), has experience as a teacher of Business Administration and Marketing, and she is an expert on research, development, and innovation projects at the Savonia University of Applied Sciences in Finland. She has also undertaken SME business development through practical field work in healthcare, industrial factories, advertising, and the tourism industries. Currently, she is preparing her doctoral thesis at the Lappeenranta University of Technology, Finland. Her research interest includes business models and organizational culture development of SMEs with an interest in what kind of common ground, effects, and connections these concepts have on each other.

\section{References}

Balasubramanian, R., \& Tiwana, A. 1999. Supporting Collaborative Process Knowledge in New Product Development Teams. Decision Support Systems, 27(1-2): 113-135.

https://doi.org/10.1016/S0167-9236(99)00045-7

Batterham, R. W., Buchbinder, R., Beauchamp, A., Dodson, S., Elsworth, G. R., \& Osborne, R. H. 2014. The OPtimising HEalth LIterAcy (Ophelia) Process: Study Protocol for Using Health Literacy Profiling and Community Engagement to Create and Implement Health Reform. BMC Public Health, 14: 694.

http:/dx.doi.org/10.1186/1471-2458-14-694

Brouwer, P., Brekelmans, M., Nieuwenhuis, L., \& Simons, R.-J. 2012. Fostering Teacher Community Development: A Review of Design Principles and a Case Study of an Innovative Interdisciplinary Team. Learning Environments Research, 15(3): 319-344. http://dx.doi.org/10.1007/s10984-012-9119-1

Brown, T. 2008. Design Thinking. Harvard Business Review, 86(6): 84-92.

Cameron, A. F., \& Webster, J. 2005. Unintended Consequences of Emerging Communication Technologies: Instant Messaging in the Workplace. Computers in Human Behavior, 21(1): 85-103.

https://doi.org/10.1016/j.chb.2003.12.001

Cormican, K., \& O'Sullivan, D. 2004. Auditing Best Practice for Effective Product Innovation Management. Technovation, 24(10): 819-829.

http://dx.doi.org/10.1016/S0166-4972(03)00013-0

Denyer, D., Tranfield, D., \& van Aken, J. E. 2008. Developing Design Propositions through Research Synthesis. Organizational Studies, 29(3): 393-413.

https://doi.org/10.1177/0170840607088020

Deshpandé, R., Farley, J. U., Webster, \& F. E. 2000. Triad Lessons: Generalizing Results on High Performance Firms in Five BusinessTo-Business Markets. International Journal of Research of Marketing, 17(4): 353-362.

https://doi.org/10.1016/S0167-8116(00)00009-4
Deshpandé, R., \& Farley, J. U. 2004. Organizational Culture, Market Orientation, Innovativeness, and Firm Performance: An International Research Odyssey. International Journal of Research in Marketing, 21(1): 3-22.

https://doi.org/10.1016/j.ijresmar.2003.04.002

Eskelinen, T., Rajahonka, M., Santti, U., \& Villman, K. 2017. Improving Internal Communication Management In SMEs: Case Study. In Proceedings of the ISPIM Innovation Forum, Toronto, Canada, March 19-22, 2017.

George, M. L. 2002. Lean Six Sigma: Combining Six Sigma Quality with Lean Speed. New York: McGraw-Hill.

Griffin, A., \& Hauser, J. R. 1996. Integrating R\&D and Marketing: A Review and Analysis of the Literature. Journal of Product Innovation Management, 13(3): 191-215. https://doi.org/10.1016/0737-6782(96)00025-2

Hamilton, M., Kass, A., \& Alter, A. E. 2016. How Collaboration Technologies Can Boost Business Performance. Outlook. Accessed June 1, 2017:

https://www.accenture.com/us-en/insight-outlook-howcollaboration-technologies-are-improving-process-workforcebusiness

Heckscher, C., \& Adler, P. S. (Eds.) 2006. The Firm as a Collaborative Community: Reconstructing Trust in the Knowledge Economy. Oxford: Oxford University Press.

Hise, R. T., O`Neal, L., Parasuraman, A., \& McNeal, J. U. 1990. Marketing/R\&D Interaction in New Product Development: Implications for New Product Success. Journal of Product Innovation Management, 7(2): 142-155. http://dx.doi.org/10.1111/1540-5885.720142

Kajanus, M., Iire, A., Eskelinen, T., Heinonen, M., \& Hansen, E. 2014. Business Model Design: New Tools for Business Systems Innovation. Scandinavian Journal of Forest Research, 29(6): 603-614.

http://dx.doi.org/10.1080/02827581.2014.949301

Katcher, B.L. 2017. How to Improve Interdepartmental Communication. Sharon, MA: Discovery Surveys Inc. http://www.discoverysurveys.com/articles/itw-017.html

Kimbell, L. 2011. Designing for Service as One Way of Designing Services. International Journal of Design, 5(2): 41-52.

Koivisto, M. 2014. Introduction to Service Design. Pake Savo Training Programme 2015 (In Finnish). Helsinki: Hellon Oy.

Maltz, E. 2000. Is All Communication Created Equal? An Investigation into the Effects of Communication Mode on Perceived Information Quality. Journal of Product Innovation Management, 17(2): $110-127$. https://doi.org/10.1016/S0737-6782(99)00030-2

Mendelson, H., \& Pillai, R. R. 1999. Information Age Organizations, Dynamics and Performance. Journal of Economic Behavior and Organization, 38(3): 253-281.

https://doi.org/10.1016/S0167-2681(99)00010-4

Miettinen, S., \& Koivisto, M. (Eds.). 2009. Designing Services with Innovative Methods: Perspectives on Service Design. Helsinki: University of Art and Design.

Moritz, S. 2005. Service Design: Practical Access to an Evolving Field. Cologne, Germany: Köln International School of Design. 


\section{Improving Internal Communication Management in SMEs}

\section{Tuomo Eskelinen, Mervi Rajahonka, Kaija Villman, and Ulla Santti}

Morelli, N. 2002. Designing Product/Service Systems: A Methodological Exploration. Design Issues, 18(3): 3-17.

http://www.jstor.org/stable/1512062

Nielsen, A. E., \& Thomsen, C. 2009. CSR Communication in Small and Medium-Sized Enterprises. A Study of the Attitudes and Beliefs of Middle Managers. Corporate Communications: An International Journal, 14(2): 176-182.

https://doi.org/10.1108/13563280910953852

Nisula, J. V. Searching for Definitions for Service Design - What Do We Mean with Service Design? In Proceedings of the Third Nordic Conference on Service Design and Service Innovation, Helsinki, Finland, February, 2012: 171-175.

Ojasalo, K. 2017. Designing a Service-Dominant Business Model in the Industrial Context. In S. Miettinen (Ed.), An Introduction to Industrial Service Design: 117-123. New York: Routledge.

Ojasalo, K., \& Ojasalo, J. 2015. Adapting Business Model Thinking to Service Logic: An Empirical Study on Developing a Service Design Tool. In J. Gummerus, \& K. Von Koskull (Eds.), The Nordic School: Service Marketing and Management for the Future: 309-333. Helsinki: CERS, Hanken School of Economics.

Pake Savo. 2015-2017. A Training Programme of Service Design. Brochure of the Pake Savo Project. Savonia University of Applied Science, Mikkeli University of Applied Science \& Aalto University.
Pervaiz, K. A. 1998. Culture and Climate for Innovation. European Journal of Innovation Management, 1(1): 30-43. https://doi.org/10.1108/14601069810199131

Proper, E., Lankhorst, M. M, Schönherr, M., Barjis, J., \& Overbeek, S. (Eds.) 2010. Proceedings of the 5th TEAR Workshop: Trends in Enterprise Architecture Research: Delft, The Netherlands, November 12, 2010.

Sanders, E. B.-N., \& Dandavate, U. 1999. Design for Experiencing: New Tools. In C. J. Overbeeke \& P. Hekkert (Eds.), Proceedings of the First International Conference on Design and Emotion, TU Delft, 1999.

Terziovski, M., Sohal, A., \& Howell, A. 2002. Best Practice in Product Innovation at Varian Australia. Technovation, 22 (9): 561-569. https://doi.org/10.1016/S0166-4972(01)00060-8

Varey, R. 1995. Internal Marketing: A Review and Some Interdisciplinary Research Challenges. International Journal of Service Industry Management, 6(1): 40-63. https://doi.org/10.1108/09564239510078849

Zeithaml, V. A., Berry, L.L., \& Parasuraman, A. 1988. Communication and Control Processes in the Delivery of Service Quality. Journal of Marketing, 52(2): 35-48. http://dx.doi.org//10.2307/1251263 